\title{
PENGEMBANGAN MODUL BRYOPHYTA BERBASIS HASIL PENELITIAN DI TAHURA NGARGOYOSO KARANGANYAR UNTUK SISWA KELAS X SMA
}

\author{
Acna Clara Aida Wati ${ }^{\left.{ }^{*}\right)}$, Tri Wiharti ${ }^{2)}$, Anwari Adi Nugroho ${ }^{3)}$ \\ ${ }^{1,2,3)}$ Program Studi Pendidikan Biologi Universitas Veteran Bangun Nusantara Sukoharjo \\ Email: acnaclara13@gmail.com
}

Diterima 24 Agustus 2019 disetujui 25 September 2019

\begin{abstract}
The purpose of this study was to 1) determine the characteristics of the module based on the identification of Bryophyta in Ngargoyoso Karanganyar Forest Park for grade X students of high school; 2) determine the feasibility of modules based on the identification of Bryophyta (Moss Plant) in Ngargoyoso Karanganyar Forest Park in terms of material aspects, aspects of module presentation, biology teachers and students. This type of research is research and developer according to Brog and Gall which was modified into 7 stages, among others is 1) research and information gathering; 2) planning; 3) initial product development; 4) trial of initial product; 5) initial product revision; 6) limited field testing; 7) second product revision. The results of this study indicate that there were studi 13 species of Bryophyta that can be used for the development of biological modules with Bryophyta material. Material expert assessment was obtained $81.89 \%$ so that it was included in the feasible category with very good qualifications, module expert judgment was obtained $83.62 \%$ so that it was included in the decent category with very good qualifications, the average assessment of practitioners of biology teachers was obtained $83.40 \%$ so it included in the feasible category with very good qualifications, and the percentage of user assessment of Grade X MIPA students was obtained $85.53 \%$ so that it was included in the decent category with very good qualifications. Based on this, it can be concluded that the biology module developed was included in the feasible category with very good qualifications and can be continued in operational tests.
\end{abstract}

Keywords: Biology Module, Bryophyta, Research Result

PENDAHULUAN

Pembelajaran biologi yang ideal merupakan pembelajaran yang memberikan kesempatan kepada siswa untuk menemukan fakta, membangun konsep, dan menemukan nilai baru. Siswa diposisikan sebagai pelaku kerja ilmiah dalam kegiatan pembelajaran biologi (Sugiharto, 2011).

Idealnya pembelajaran biologi mempunyai karakteristik melibatkan siswa secara aktif, pendekatakan kolaboratif, dan menekankan hasil (kompetensi) akademik siswa dengan menegaskan peran guru sebagai fasilitator. Dengan demikian pembelajaran biologi bertujuan untuk membantu siswa mengembangkan keterampilan berpikir kritis dan kreatif, membangun penguasaan konsep esensial, dan bentuk-bentuk dasar berfikir saintifik, serta membangun kepercayaan diri dalam menyelesaikan suatu masalah. (Sugiharto, 2011).

Penelitian tentang pembelajaran biologi yang ideal telah dilaksakan pada tanggal 12 Desember 2018 dengan melakukan observasi dan wawancara yang melibatkan siswa kelas $\mathrm{X}$ dan guru biologi di SMA N 1 Kerjo, yang hasilnya menunjukkan bahwa proses pembelajaran biologi di SMA N 1 Kerjo masih belum ideal. Hal ini didukung dengan proses pembelajaran di kelas masih menggunakan metode konvensional, hasil belajar siswa pada mata pelajaran biologi masih rendah, serta bahan ajar yang digunakan berupa modul yang belum memenuhi kaidah penulisan modul yang baik dan benar, hal ini dibuktikan dengan hasil 
penilaian kelengkapan modul yang digunakan di SMA N 1 Kerjo menurut Depdiknas (2008) menunjukkan nilai $46 \%$. Modul yang digunakan di SMA N 1 Kerjo hanya terdiri dari komponen judul, daftar isi, peta informasi, daftar tujuan kompetensi, uraian materi, penugasan, tes akhir. Sedangkan, komponen isi modul menurut Depdiknas (dikutip dari Wicaksono, 2015:4) terdiri atas bagian pembuka (judul, daftar isi, peta informasi, daftar tujuan kompetensi, tes awal), bagian inti (tinjauan materi, hubungan dengan materi lain, uraian materi, penugasan, rangkuman), dan bagian akhir (glosarium, tes akhir, indeks). Penulisan modul yang belum memenuhi kaidah penulisan yang baik dan benar menjadi salah satu faktor rendahnya hasil belajar biologi di SMA N 1 Kerjo. Hal ini ditunjukan dengan rata-rata presentase ketuntasan nilai ulangan harian biologi kelas $\mathrm{X}$ yaitu 3,6\%, hal ini sesuai dengan pendapat Sugiarto (2016) yang menyatakan bahwa penelitian dan pengembangan modul dapat digunakan untuk meningkatkan pemahaman konsep.

Upaya untuk mengatasi permasalahan tersebut adalah dengan melakukan pengembangan modul pembelajaran berbasis penelitian (research). Modul adalah bahan ajar yang ditulis dengan tujuan agar siswa dapat belajar secara mandiri atau tanpa bimbingan guru. Modul harus menggambarkan kompetensi dasar yang akan dicapai oleh siswa, menggunakan bahasa yang baik, dan dilengkapi dengan ilustrasi (Majid, 2013). Melalui modul pembelajaran berbasis penelitian (research), siswa dapat belajar lebih banyak melalui pengalaman langsung, mendapatkan bekal keterampilan, serta menilai sendiri hasil pekerjaan yang telah dilakukan. Hal ini penting untuk melatih inisiatif, kemandirian, dan kepercayaan diri peserta didik dalam belajar (Fitriyati, Mufti \& Lestari, 2015). Hasil penelitian Yahya (dikutip dari Fitriyati, Mufti \& Lestari, 2015:119) menyatakan bahwa pengembangan kurikulum berbasis penelitian telah meningkatkan kualitas pembelajaran, dan ruang keterlibatan siswa dalam proses pembelajaran.
Pengembangan modul telah dilakukan oleh beberapa penelitian diantaranya dilakukan oleh Lestari (2017) menunjukkan bahwa modul materi ekosistem yang berbasis pada kearifan lokal di Goa Kreo termasuk dalam kategori layak. Pada penelitian tersebut belum mengarah pada hasil penelitian yang digunakan sebagai bahan modul. Pengembangan modul materi ekosistem berbasis potensi lokal yang dilakukan oleh Prabowo, Nurmiyati \& Maridi (2016) menunjukkan bahwa modul memiliki kategori layak. Namun penelitian tersebut masih belum mengarah pada hasil penelitian. Berdasarkan hasil-hasil pengembangan modul yang dilakukan oleh peneliti sebelumnya, maka dikembangkan modul biologi berbasis hasil penelitian.

Pengembangan modul berbasis penelitian (research) difokuskan pada hasil identifikasi Bryophyta (Tumbuhan Lumut) di Taman Hutan Raya Ngargoyoso, Karanganyar. Alasan pemilihan Taman Hutan Raya Ngargoyoso, Karanganyar sebagai lokasi penelitian karena lokasi tersebut dekat dengan SMA N 1 Kerjo. Selain itu belum pernah ada penelitian tentang Bryophyta (Tumbuhan Lumut) di Taman Hutan Raya Ngargoyoso, Karanganyar yang hasil penelitiannya digunakan sebagai sumber belajar. Pemilihan Bryophyta (Tumbuhan Lumut) sebagai objek penelitian karena materi Bryophyta (Tumbuhan Lumut) berisi konsep-konsep penting yang tujuannya dapat mengantarkan siswa ke objek yang lebih nyata.

Modul Bryophyta ini dikembangkan berdasarkan Kurikulum 2013, menggunakan Kompetensi Inti (KI) 3. Memahami, menerapkan, menganalisis pengetahuan faktual, konseptual, prosedural berdasarkan rasa ingintahunya tentang ilmu pengetahuan, teknologi, seni, budaya, dan humaniora dengan wawasan kemanusiaan, kebangsaan, kenegaraan, dan peradaban terkait fenomena dan kejadian, serta menerapkan pengetahuan prosedural pada bidang kajian yang spesifik sesuai dengan bakat dan minatnya untuk memecahkan masalah, dan Kompetensi Dasar (KD) yaitu 3.7 Menerapkan prinsip 
klasifikasi untuk menggolongkan tumbuhan ke dalam divisio berdasarkan pengamatan morfologi dan metagenesis tumbuhan serta mengaitkan peranannya dalam kelangsungan kehidupan di bumi pada pokok bahasan Tumbuhan ciri-ciri morfologis, metagenesis, peranan dalam keberlangsungan hidup di bumi.

Modul Bryophyta yang dikembangkan berisi komponen-komponen modul yang sesuai dengan standar pembuatan modul menurut Departemen Pendidikan Nasional (Depdiknas) 2008. Modul ini disajikan dalam bentuk buku yang berisi pokok bahasan Plantae khususnya Bryophyta (Tumbuhan Lumut) yang disertai hasil identifikasi Bryophyta (Tumbuhan Lumut) di Taman Hutan Raya Ngargoyoso Karanganyar. Materi Bryophyta (Tumbuhan Lumut) dalam modul meliputi pengertian dan ciri-ciri, habitat dan cara hidup, reproduksi, siklus hidup atau metagenesis, manfaat dan hasil identifikasi Bryophyta (Tumbuhan Lumut) di Taman Hutan Raya Ngargoyoso Karanganyar. Modul ini juga dibuat semenarik mungkin, sehingga materi yang ada di dalam modul dapat dipahami oleh siswa dengan baik.

Dalam penelitian dan pengembangan ini memiliki tujuan (1) mengetahui karakteristik modul berbasis hasil identifikasi Bryophyta (Tumbuhan Lumut) di Taman Hutan Raya Ngargoyoso Karanganyar untuk siswa kelas X SMA, (2) mengetahui kelayakan (valid dan praktis) modul berbasis hasil identifikasi Bryophyta (Tumbuhan Lumut) di Taman Hutan Raya Ngargoyoso Karanganyar ditinjau dari aspek materi, aspek penyajian modul, guru biologi dan siswa.

\section{METODE}

Prosedure penelitian pengembangan modul Bryophyta ini dilakukan dengan mengacu pada langkah-langkah penelitian dan pengembangan (Research and Development) menurut Borg and Gall yang telah dimodifikasi menjadi 7 tahap (Nugroho, Hanik \& Harsono, 2017) yaitu penelitian dan pengumpulan informasi, perencanaan, pengembangan produk awal, uji coba produk awal, revisi produk awal, uji lapangan terbatas, revisi produk kedua. Pelaksanaan penelitian dan pngembangan modul dilaksanakan pada Desember 2018 Agustus 2019. Prosedur pengembangan modul Bryophyta dapat ditunjukkan pada gambar 1.

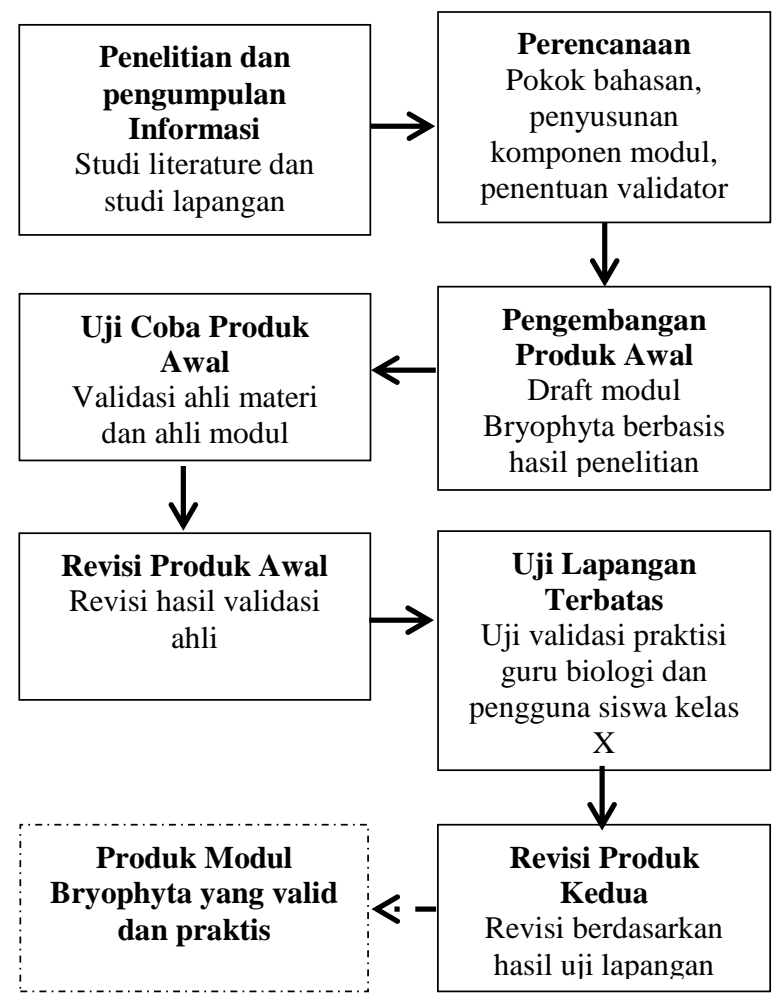

Gambar 1. Prosedure Pengembangan Modul

Penelitian pengembangan ini menggunakan dua teknik analisis data, yaitu (a) analisis deskriptif kualitatif digunakan untuk mengolah data hasil review ahli materi, ahli modul, guru biologi dan siswa kelas $X$ MIPA pada tahap uji coba produk awal dan uji lapangan terbatas. Teknik analisis data ini dilakukan dengan mengelompokkan informasi-informasi dari data kualitatif yang berupa masukan, tanggapan, kritik, dan saran perbaikan yang terdapat pada angket/kuesioner. (b) analisis deskriptif persentase digunakan untuk mengolah data yang diperoleh melalui angket/kuesioner. Data yang diperoleh dari hasil penilaian ahli materi, ahli modul, siswa dan guru biologi kemudian dianalisis untuk mengetahui tingkat kelayakan modul, dengan cara menghitung skor yang dicapai 
dari seluruh aspek yang dinilai kemudian Analisis data hasil penilaian modul biologi dihitung menggunakan rumus 1 . sebagai berikut (Ali, 1992 dalam Nugroho \& Subiyantoro, 2017):

$$
N=\frac{k}{N k} \times 100 \%
$$

Keterangan :

$\mathrm{N} \quad$ : Persentase aspek

k : Skor yang dicapai

Nk : Skor maksimal

Sedangkan kriteria kelayakan modul dapat ditunjukkan pada tabel 1 .

Tabel 1. Kriteria Kelayakan Modul

\begin{tabular}{ccc}
\hline Interval Skor & Kualifikasi & Kategori \\
\hline $81 \leq \mathrm{N}<100$ & Sangat Baik & Layak \\
$62 \leq \mathrm{N}<81$ & Baik & Layak \\
$43 \leq \mathrm{N}<62$ & Cukup & Tidak Layak \\
$24 \leq \mathrm{N}<43$ & Kurang & Tidak Layak \\
\hline
\end{tabular}

\section{HASIL DAN PEMBAHASAN \\ Penelitian dan Pengumpulan Informasi}

Tahap penelitian dan pengumpulan informasi ini meliputi studi literatur dan studi lapangan. Hal ini sesuai dengan pendapat Nugroho \& Subiyantoro (2017) yang menyatakan bahwa tahap penelitian dan pengumpulan informasi dilakukan analisis kebutuhan melalui observasi lapangan dan studi pustaka. Studi literatur pada tahap ini terdiri dari pengumpulan sumber-sumber informasi yang digunakan untuk mengembangkan materi dalam modul. Sedangkan, studi lapangan pada meliputi kegiatan wawancara baik dengan siswa kelas dan guru biologi di SMA N 1 Kerjo serta kegiatan observasi/pengamatan Bryophyta (Tumbuhan Lumut).

\section{Perencanaan}

$\begin{array}{crr}\text { Tahap } & \text { perencanaan meliputi } \\ \text { penentuan pokok bahasan } & \text { yang }\end{array}$ dikembangkan dalam modul, penyusunan komponen modul dan penentuan validator. Pokok bahasan yang digunakan pada pengembangan modul ini yaitu Plantae sub bab Bryophyta (Tumbuhan Lumut). Kemudian penyusunan modul disesuaikan dengan buku pedoman penulisan modul yang baik dan benar menurut Departemen Pendidikan Nasional tahun 2008. Modul biologi yang dikembangkan memiliki karakteristik bagian pembuka (cover modul, halaman francis, redaksi modul, kata pengantar, pendahuluan, kompetensi, pedoman penggunaan modul, daftar isi, daftar gambar, daftar tabel, peta konsep, kata kunci, test awal), bagian inti (uraian materi, tinjauan materi, penugasan, daftar bryophyta (tumbuhan lumut), kamu perlu tahu, kisah teladan, sains up to date, relationship of biology, refleksi diri, ringkasan materi), bagian penutup (uji kompetensi, kunci jawaban, rubrik penilaian, glosarium, indeks, daftar pustaka). Selanjutnya penentuan validator terdiri dari ahli materi, ahli penyajian modul, praktisi guru biologi dan pengguna sisiwa kelas X.

\section{Pengembangan Produk Awal}

Tahap pengembangan modul meliputi merancang/mendesain draft modul untuk mempermudah dalam penyusunan modul pembelajaran, membuat draft modul sesuai dengan buku pedoman penulisan modul yang baik dan benar menurut Departemen Pendidikan Nasional tahun 2008, dan memproduksi draft modul yang sudah disusun ke dalam bentuk buku yang dapat dilihat pada gambar 2 .

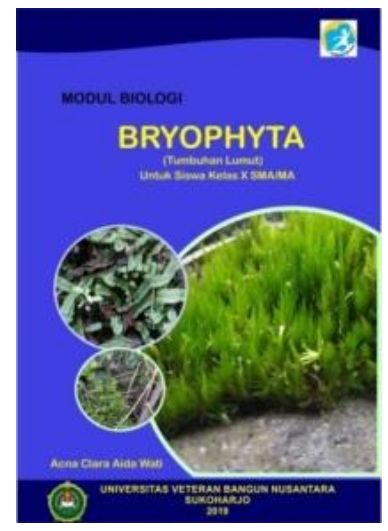

Gambar 2. Produk draft modul

\section{Uji Coba Produk Awal}

Uji coba produk awal dilakukan untuk memperoleh evaluasi kualitatif dan kuantitatif dari draft modul yang telah 
disusun. Uji coba produk awal dilakukan di Universitas Veteran Bangun Nusantara Sukoharjo dengan memberikan lembar penilaian angket/kuesioner kepada validator untuk menilai draft modul. Validator pada uji coba produk awal terdiri dari ahli materi dan ahli modul. Hal ini sesuai dengan pendapat Rohmiyati, Ashadi \& Utomo (2016) dalam Nugroho \& Subiyantoro (2017) yang menyatakan bahwa tahap uji coba produk awal berisi kegiatan validasi draft modul kepada validator ahli. Validasi ahli materi mencakup dimensi sikap spiritual, dimensi sikap sosial, dimensi pengetahuan, dan dimensi keterampilan. Selain menvalidasi draft modul ahli materi juga memberikan saran yang dapat dilihat pada tabel 1 .

Tabel 1. Saran dari Ahli Materi

\begin{tabular}{lrl}
\hline \multicolumn{2}{c}{ Saran } & \multicolumn{2}{c}{ Kesimpulan } \\
\hline Penyusunan & materi & Layak, dengan revisi \\
dalam & modul & sesuai masukan \\
disesuaikan & dengan & \\
Kompetensi & Dasar \\
(KD) & & \\
Perlu menambahkan & \\
keterangan bahwa & \\
Jamur (Fungi) & masuk \\
kingdom lain. & \\
Gambar & asli \\
disandingkan dengan \\
gambar skema pada \\
halaman 3, 11, dan 12. \\
Menggunakan gambar \\
yang sesuai $\quad$ untuk \\
halaman 6. \\
Kisah teladan dikutip \\
disesuaikan dengan \\
lokasi penelitian. \\
Teliti dalam penjilidan
\end{tabular}

Validasi ahli modul mencakup aspek teknik penyajian, aspek pendukung penyajian materi, aspek penyajian pembelajaran, dan aspek kelengkapan penyajian. Selain menvalidasi draft modul, ahli modul juga memberikan saran yang dapat dilihat pada tabel 2 .

Tabel 2. Saran dari Ahli Modul

\begin{tabular}{|c|c|}
\hline Saran & Kesimpulan \\
\hline $\begin{array}{l}\text { Penulisan daftar pustaka spasinya } \\
\text { dirapikan. }\end{array}$ & $\begin{array}{l}\text { Layak, dengan } \\
\text { revisi sesuai } \\
\text { masukan }\end{array}$ \\
\hline $\begin{array}{l}\text { Jarak spasi daftar pustaka yang } \\
\text { satu dengan yang lain agar } \\
\text { dirapatkan agar tidak terlalu }\end{array}$ & \\
\hline
\end{tabular}

\begin{tabular}{l}
\hline renggang. \\
Pemilihan warna tulisan pada \\
draft cover seharusnya \\
menggunakan warna yang kontras \\
sehingga tulisan dalam cover \\
dapat terlihat.
\end{tabular}

\section{Revisi Produk Awal}

Revisi produk awal dilakukan untuk memperbaiki draft modul berdasarkan saran dari ahli materi dan ahli modul sebelum di uji pada uji lapangan terbatas. Hal ini sesuai dengan pendapat Sulistyaningrum, Karyanto \& Sunarno (2015) yang menyatakan bahwa berdasarkan validasi yang dilakukan diperoleh masukan dan saran untuk perbaikan sebelum modul diuji dalam skala terbatas. Berdasarkan hasil uji coba produk awal dilakukan perbaikan terhadap saran dan masukan yang diberikan oleh ahli materi yang dapat dilihat pada tabel 3 .

Tabel 3. Revisi Ahli Materi

\begin{tabular}{|c|c|}
\hline Aspek Materi & Perbaikan \\
\hline $\begin{array}{l}\text { Perlu menambahkan } \\
\text { keterangan bahwa Jamur } \\
\text { (Fungi) masuk kingdom lain. }\end{array}$ & 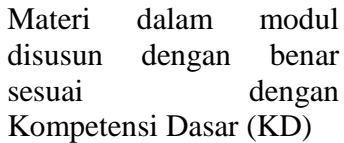 \\
\hline $\begin{array}{l}\text { Gambar asli disandingkan } \\
\text { dengan gambar skema pada } \\
\text { halaman } 3,11 \text {, dan } 12 \text {. }\end{array}$ & $\begin{array}{ll}\text { Keterangan kingdom } \\
\text { Fungi (Jamur) bahwa } \\
\text { tidak termasuk dalam } \\
\text { kingdom Plantae } \\
\text { ditambahkan }\end{array}$ \\
\hline $\begin{array}{l}\text { Menggunakan gambar yang } \\
\text { sesuai untuk halaman } 6 \text {. }\end{array}$ & 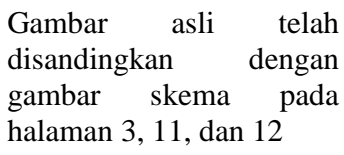 \\
\hline $\begin{array}{l}\text { Kisah teladan dikutip } \\
\text { disesuaikan dengan lokasi } \\
\text { penelitian. } \\
\text { Teliti dalam penjilidan }\end{array}$ & $\begin{array}{l}\text { Gambar alat reproduksi } \\
\text { Bryophyta pada halaman } \\
6 \text { sudah sesuai } \\
\text { Kisah teladan dalam } \\
\text { modul dikutip dari lokasi } \\
\text { sekitar kawasan Tahura } \\
\text { Ngargoyoso }\end{array}$ \\
\hline $\begin{array}{l}\text { Perlu menambahkan } \\
\text { keterangan bahwa Jamur } \\
\text { (Fungi) masuk kingdom lain. }\end{array}$ & $\begin{array}{l}\text { Penjilidan sudah diteliti } \\
\text { sehingga tidak terbalik }\end{array}$ \\
\hline
\end{tabular}

Perbaikan terhadap hasil validasi ahli modul juga dilakukan dan dapat dijelaskan pada tabel 4.

Tabel 4. Revisi Ahli Modul

\begin{tabular}{lll}
\hline \multicolumn{2}{c}{ Aspek Modul } & \multicolumn{1}{c}{ Perbaikan } \\
\hline \multicolumn{2}{l}{ Penulisan daftar pustaka } & Spasi pada daftar \\
spasinya dirapikan. & pustaka sudah dirapikan \\
Jarak spasi daftar & Jarak spasi antar daftar \\
pustaka yang satu & pustak sudah dirapikan \\
dengan yang lain agar & sehingga jaraknya sama \\
dirapatkan agar tidak & \\
\hline
\end{tabular}


terlalu renggang.

Pemilihan warna tulisan Warna tulisan pada draft

pada draft cover cover modul sudah

seharusnya kontras

menggunakan warna

yang kontras sehingga

tulisan dalam cover

dapat terlihat.

Setelah dilakukan perbaikan terhadap draft modul, kemudian dilakukan analisis validasi draft modul oleh ahli materi dan ahli modul yang menunjukkan hasil persentase penilaian draft modul $81,89 \%$ sehingga termasuk dalam kategori layak dengan kualifikasi sangat baik hal ini sesuai dengan pendapat Ali (1992) dalam Nugroho \& Subiyantoro (2017) yang menyatakan bahwa persentase aspek skor yang diperoleh 81 100 termasuk dalam kategori layak dengan kualifikasi sangat baik dan sesuai dengan pendapat Arikunto (1998) yang menyatakan bahwa persentase tingkat kelayakan produk yang diperoleh rentang 81 - 100 termasuk dalam kriteria sangat layak dan hasil validasi dapat dijelaskan pada tabel 5 .

Tabel 5. Hasil validasi draft modul oleh ahli materi dan ahli modul

\begin{tabular}{ccc}
\hline Validator & Persentase & Kualifikasi \\
\hline Ahli Materi & $81,89 \%$ & Sangat Baik \\
Ahli Modul & $83,62 \%$ & Sangat Baik \\
\hline Rata-rata & $82,75 \%$ & Sangat Baik \\
\hline
\end{tabular}

\section{Uji Lapangan Terbatas}

Uji lapangan terbatas dilaksanakan di SMA Negeri 1 Kerjo dengan tujuan untuk memperoleh hasil evaluasi kualitatif dan kuantitatif dari produk utama yaitu modul biologi. Uji lapangan terbatas dilaksanakan dengan memberikan lembar penilaian angket/kuesioner kepada praktisi dan pengguna untuk menilai modul biologi yang telah direvisi sebelumnya. Praktisi dan pengguna pada uji lapangan terbatas ini terdiri dari 2 guru biologi dan 10 siswa kelas X MIPA yang telah mendapat materi tentang Bryophyta (Tumbuhan Lumut). Uji lapangan terbatas dilaksanakan pada tanggal 23-24 Juli 2019 .

Penilaian praktisi guru biologi terhadap modul biologi mencakup dimensi sikap spiritual, dimensi sikap sosial, dimensi pengetahuan, dimensi keterampilan aspek teknik penyajian, aspek pendukung penyajian materi, aspek penyajian pembelajaran, dan aspek kelengkapan penyajian. Selain memberikan penilaian, guru biologi juga memberikan saran yang dapat dijelaskan pada tabel 6 .

Tabel 6. Saran dari Praktisi Guru Biologi

\begin{tabular}{clll}
\hline Guru & \multicolumn{1}{c}{ Saran } & \multicolumn{2}{c}{ Kesimpulan } \\
\hline Guru 1 & $\begin{array}{l}\text { Modul ini sudah bagus, } \\
\text { namun dalam modul ini } \\
\text { masih perlu ditambah }\end{array}$ & $\begin{array}{l}\text { Layak, } \\
\text { revisi }\end{array}$ & dengan \\
& saran & \\
lagi latihan soal. & & \\
Guru 2 & Modul ini sudah bagus & Layak, dengan \\
& dan layak untuk & revisi & sesuai \\
& digunakan sebagai & saran & \\
& bahan ajar siswa kelas & & \\
& X MIPA. Namun saran & & \\
& saya untuk menambah \\
& hubungan Bryophyta & & \\
dengan materi/bidang & & \\
ilmu lain & & \\
\hline
\end{tabular}

Proses uji lapangan terbatas dengan pengguna siswa siswa diminta untuk mengisi angket/kuesioner dan memberikan saran terhadap modul biologi. Hal ini sesuai dengan penelitian Sulistyaningrum, Karyanto \& Sunarno (2015) yang menyatakan bahwa tahap uji lapangan terbatas dilakukan tehadap 10 orang siswa. Saran yang diberikan oleh siswa kelas $\mathrm{X}$ dapat dijelaskan pada tabel 7.

Tabel 7. Saran dari Pengguna Siswa

\begin{tabular}{cll} 
Siswa & \multicolumn{1}{c}{ Saran } & Kesimpulan \\
\hline Siswa 1 & $\begin{array}{l}\text { Sudah lengkap dan } \\
\text { materinya mudah } \\
\text { dipahami }\end{array}$ & Layak \\
Siswa 2 & $\begin{array}{l}\text { Modul sudah disusun } \\
\text { dengan baik dan lengkap, } \\
\text { gambar jelas sehingga } \\
\text { mudah dipahami } \\
\text { Materi sudah } \\
\text { Siswa 3 }\end{array}$ & Layak \\
& $\begin{array}{l}\text { disampaikan secara } \\
\text { lengkap dan menyeluruh } \\
\text { Alangkah baiknya gambar } \\
\text { lumut dalam modul lebih } \\
\text { diperjelas }\end{array}$ & Layak \\
& & \\
\hline
\end{tabular}

\section{Revisi Produk Kedua}

Revisi produk kedua dilakukan berdasarkan saran dari praktisi guru biologi dan pengguna siswa kelas X MIPA pada tahap uji lapangan terbatas. Berdasarkan saran yang diperoleh dari praktisi guru biologi pada uji lapangan terbatas 
dilakukan perbaikan yang dapat dijelaskan pada tabel 8 .

Setelah dilakukan perbaikan modul biologi kemudian dilakukan analisis hasil penilaian oleh praktisi guru biologi yang hasilnya menunjukkan bahwa hasil persentase penilaian modul biologi 83,62\% sehingga termasuk dalam kategori layak dengan kualifikasi sangat baik hal ini sesuai dengan pendapat Ali (1992) dalam Nugroho \& Subiyantoro (2017) yang menyatakan bahwa persentase aspek skor yang diperoleh 81 - 100 termasuk dalam kategori layak dengan kualifikasi sangat baik dan sesuai dengan pendapat Arikunto (1998) yang menyatakan bahwa persentase tingkat kelayakan produk yang diperoleh rentang 81 - 100 termasuk dalam kriteria sangat layak yang hasil penilaiannya dapat dijelaskan pada tabel 9 .

Tabel 8. Revisi Praktisi Guru Biologi

\begin{tabular}{llrl}
\hline Guru & \multicolumn{2}{c}{ Saran } & \multicolumn{2}{c}{ Perbaikan } \\
\hline Guru 1 & $\begin{array}{l}\text { Modul ini sudah } \\
\text { bagus, namun dalam }\end{array}$ & $\begin{array}{l}\text { Ladihan soal } \\
\text { pada uji } \\
\text { modul ini masih } \\
\text { kompetensi }\end{array}$ \\
& perlu ditambah lagi & sudah \\
latihan soal. & ditambahkan \\
Guru 2 & Modul ini sudah & Hubungan \\
& bagus dan layak & materi \\
& untuk digunakan & Bryophyta \\
& sebagai bahan ajar & dengan \\
& siswa kelas X MIPA. & materi/bidang \\
& Namun saran saya & ilmu yang lain \\
& untuk menambah & sudah \\
& hubungan Bryophyta & ditambahkan \\
& dengan & \\
materi/bidang ilmu & \\
lain & & \\
\hline
\end{tabular}

Tabel 9. Hasil penilaian guru biologi

\begin{tabular}{ccl}
\hline Guru & Persentase & Kualifikasi \\
\hline Guru Biologi 1 & $83,6 \%$ & Sangat Baik \\
Guru Biologi 2 & $83,2 \%$ & Sangat Baik \\
\hline Rata-rata & $82,4 \%$ & Sangat Baik \\
\hline
\end{tabular}

Kemudian berdasarkan penilaian yang dilakukan oleh siswa kelas $\mathrm{X}$, diperoleh saran dan masukan yang kemudian dilakukan perbaikan terhadap modul biologi yang dapat dijelaskan pada pada tabel 10 .

Tabel 10. Saran dari Siswa

\begin{tabular}{|c|c|c|}
\hline Siswa & Saran & Perbaikan \\
\hline Siswa 1 & Modul biologi ini & Gambar \\
\hline
\end{tabular}

$\begin{array}{ll}\text { sudah baik namun } & \text { spesies } \\ \text { alangkah baiknya } & \text { Bryophyta } \\ \text { gambar lumut } & \text { (Tumbuhan } \\ \text { dalam modul lebih } & \text { Lumut) sudah } \\ \text { diperjelas } & \begin{array}{l}\text { diperjelas di } \\ \text { dalam modul }\end{array} \\ \end{array}$

Setelah dilakukan perbaikan modul biologi kemudian dilakukan analisis hasil penilaian oleh pengguna guru biologi yang hasilnya menunjukkan bahwa hasil persentase penilaian modul biologi $85,59 \%$ sehingga termasuk dalam kategori layak dengan kualifikasi sangat baik hal ini sesuai dengan pendapat Ali (1992) dalam Nugroho \& Subiyantoro (2017) yang menyatakan bahwa persentase aspek skor yang diperoleh 81 - 100 termasuk dalam kategori layak dengan kualifikasi sangat baik dan sesuai dengan pendapat Arikunto (1998) yang menyatakan bahwa persentase tingkat kelayakan produk yang diperoleh rentang 81 - 100 termasuk dalam kriteria sangat layak yang hasil penilaiannya dapat dijelaskan pada tabel 11 .

Tabel 11. Hasil Penilaian Siswa kelas X

\begin{tabular}{lcc}
\hline Siswa & Persentase & Kualifikasi \\
\hline Siswa 1 & $84,0 \%$ & Sangat Baik \\
Siswa 2 & $88,8 \%$ & Sangat Baik \\
Siswa 3 & $88,8 \%$ & Sangat Baik \\
Siswa 4 & $82,7 \%$ & Sangat Baik \\
Siswa 5 & $80,6 \%$ & Baik \\
Siswa 6 & $83,6 \%$ & Sangat Baik \\
Siswa 7 & $89,6 \%$ & Sangat Baik \\
Siswa 8 & $85,7 \%$ & Sangat Baik \\
Siswa 9 & $87,9 \%$ & Sangat Baik \\
Siswa 10 & $83,6 \%$ & Sangat Baik \\
\hline Rata-rata & $85,53 \%$ & Sangat Baik \\
\hline
\end{tabular}

Berdasarkan hasil pengembangan modul Bryophyta berbasis hasil penelitian di Tahura Ngargoyoso Karanganyar untuk siswa kelas $\mathrm{X}$ diperoleh modul yang layak (valid dan praktis) sehingga diharapkan modul ini dapat diimplementasikan untuk siswa kelas X SMA pada mata pelajaran biologi. Modul ini diharapkan dapat membuat siswa belajar secara mandiri., hal ini sesuai dengan penelitian dari Fitriyati, Mufti \& Lestari (2015) yang menyatakan bahwa pengembangan modul berbasis penelitian dapat melatih kemandirian siswa dalam belajar. Selain itu, modul Bryophyta 
yang berisi hasil penelitian dapat menambah pemahaman konsep materi Bryophyta sehingga hasil belajar siswa dapat maksimal. Hal ini sesuai dengan pendapat Sugiarto (2016) yang menyatakan bahwa modul biologi dapat digunakan untuk meningkatkan pemahaman konsep.

\section{SIMPULAN}

Pengembangan modul biologi Bryophyta berbasis penelitian (research) memiliki karakteristik bagian pembuka (cover modul, halaman francis, redaksi modul, kata pengantar, pendahuluan, kompetensi, pedoman penggunaan modul, daftar isi, daftar gambar, daftar tabel, peta konsep, kata kunci, test awal), bagian inti (uraian materi, tinjauan materi, penugasan, daftar bryophyta (tumbuhan lumut), kamu perlu tahu, kisah teladan, sains up to date, relationship of biology, refleksi diri, ringkasan materi), bagian penutup (uji kompetensi, kunci jawaban, rubrik penilaian, glosarium, indeks, daftar pustaka). Kemudian hasil penilaian modul biologi oleh validator ahli materi menunjukkan persentase $81,89 \%$ (layak/sangat baik). Penilaian oleh validator ahli modul menunjukkan persentase 83,62 \% (layak/sangat baik). Penilaian oleh 2 guru biologi menunjukkan rata-rata persentase 83,4\% (layak/sangat baik). Penilaian oleh 10 siswa kelas X MIPA SMA N 1 Kerjo menunjukkan rata-rata persentase 85,53\% (layak/sangat baik). Sehingga modul biologi yang dikembangkan layak (valid dan praktis) untuk dilanjutkan pada uji operasional.

\section{DAFTAR PUSTAKA}

Ali, M. (1992). Strategi Penelitian Pendidikan. Bandung: Angkasa.

Arikunto, Suharsimi. 2009. Prosedur Penelitian : Suatu Pendekatan Praktek, Edisi Revisi. Jakarta: PT. Rieneke Cipta

Borg, W.R \& Gall, M.D. (1983). Educational Research an Introduction.USA: Pearson.

Departemen Pendidikan Nasional (Depdiknas). (2008). Penulisan modul. Jakarta: Direktorat Jenderal
Peningkatan Mutu Pendidik Dan Tenaga Kependidikan.

Fitriyati, U., Mufti, N., \& Lestari, U. (2015). Pengembangan Modul Berbasis Riset Pada Matakuliah Bioteknologi. Jurnal Pendidikan Sains, 3(3), 118-129.

Hasmiati, W., Adnan, A., \& Hiola, F. (2018, October). Potensi Keragaman Bryophyta di Kabupaten Enrekang sebagai Sumber Belajar di SMA. In Seminar Nasional Biologi.

Majid, A. (2013). Perencanaan pembelajaran. Bandung: PT Remaja Rosdakarya.

Nugroho, A. A., Hanik, N. R., \& Harsono, S. (2017). Pengembangan Modul Biologi Molekuler Berbasis Learning Cycle 7E untuk Mahasiswa Pendidikan Biologi. Jurnal Edukasi Matematika dan Sains, 5(1), 1-7.

Nugroho, A. A., \& Subiyantoro, S. (2017). Pengembangan Modul Sistematika Tumbuhan Tinggi Berbasis Guided Discovery untuk Mengembangkan Kemampuan Berpikir Kritis Mahasiswa Pendidikan Biologi. BIOPEDAGOGI, 6(2), 19-24.

Onah. (2008). Pengaruh Penggunaan Metode Kuliah Lapangan (Field Trip) Terhadap Hasil Belajar Taksonomi Tumbuhan Tingkat Rendah. (Skripsi, Universitas Islam Negeri Syarif Hidayatullah Jakarta, 2008).

Rohmiyati, N., Ashadi, A., \& Utomo, S. B. (2016). Pengembangan modul kimia berbasis inkuiri terbimbing pada materi reaksi oksidasi-reduksi. Jurnal Inovasi Pendidikan IPA, 2(2), 223-229.

Sugiarto, D. (2016). Pengembangan Modul Anatomi Reptil Di Daerah Aliran Sungai Maospati Magetan Untuk Meningkatkan Pemahaman Konsep Mata Kuliah Struktur Hewan Di Ikip Pgri Madiun. Florea: Jurnal Biologi dan Pembelajarannya, 3(1), 1-4.

Sugiharto, B. (2011). Konsepsi Guru IPA Biologi SMP Se-Surakarta tentang Hakikat Biologi sebagai Sains. In 
Prosiding Seminar Biologi

(Vol.8,No.1).

Sulistyaningrum, D. E., Karyanto, P., \&

Sunarno, W. (2015). Pengembangan

Modul Berbasis Model Pembelajaran

Arias untuk Memberdayakan Motivasi dan Berpikir Kritis Siswa pada Materi Ekosistem. Inkuiri, 4(1), 104-116.

Wicaksono, W., Sutrino, Supri, E. M. (2015).

Pengembangan modul pembelajaran online sebagai media pembelajaran pada mata pelajaran gambar teknik kelas $\mathrm{X}$ teknik gambar bangunan di SMK Negeri 2 Sukoharjo. Indonesian Journal of Civil Engineering Education, 2, h. 3-5. DOI: 10.20961/ijcee.v2i2.17940. 